\title{
9. THE CRITICAL ROLE OF ART EDUCATION IN COMMUNITY BUILDING AS VIEWED BY ART TEACHERS. A QUALITATIVE STUDY
}

\author{
Gabriela Monica Assante, Florin Enescu ${ }^{272}$
}

\begin{abstract}
The present study aims to describe the ways in which art education impacts community life through art products. The sample consists of 32 teachers/creators in various fields of work such as fine arts, composition, literature, musical interpretation, choreography and acting. Categorical content analysis is used for data analysis. The highest-ranking emerging theme is related to the means of educational intervention in the community through art. Artistic education leads to empowerment and emancipation by provoking people to think differently while the exposure to artistic creations has a therapeutic effect and contributes to identifying new ways of action. Artists in the role of teachers feel a responsibility both for the educational process and also for the emotional message that their creative product transmits to the audience.
\end{abstract}

Key words: artistic education, community, art, teachers

\section{Introduction}

In the scientific literature as well as in the collective thinking is posited the idea of the artist as an egocentric, self-sufficient individual. From this standpoint, art is believed to be neutral, created for aesthetic reasons to be enjoyed and to evoke positive emotions, and not for moral or social reasons (Gablik, 1995). Furthermore, there is also the assumption that any human action is determined, or even multiply determined, by social, psychological and neurological factors. As we have previously mentioned, there is also the idea that artists usually concentrate on the individual at the expense of broader social issues. Even in this case, there are biographical, psychological and social reasons for most of the actions an individual performs. It can be argued that all actions are determined in some way; i.e. some actions are not free but rather are reactions caused by a direct external force. Some actions are not perceived as free by the agents because they are performed habitually, without the exercise of choice, and some actions are free in that the agent makes a deliberate choice of what to do, and are not in any way constrained. This is the primary example of a voluntary act (Wolff, 1990).

The perspective on art and artists as neutral agents may misrepresent the other salient roles that art, artists and educators can have in community-building, cultural affirmation and articulating a need for change. In these broader social functions, the boundaries between art, education and social change fade. Artists can also have simultaneous roles as educators and social change agents. These

\footnotetext{
${ }^{272}$ Candidate Doctoral, “Alexandru Ioan Cuza” University from Iaşi, Roma, email: panzaru.monica@ yahoo.com, florinescu@yahoo.com
} 
roles have no predefined order and, in different contexts, one may take precedence over the others. The intersection of these roles leads to dynamic manifestations influenced by the emerging needs and contexts of a collaborating community. The artist who is an educator as well as a social change agent works in a community and is dedicated to social change; thus, their role is significantly different from artists or teachers as we have experienced them. They represent vital aspects of our conception of what community art education and any educator can be (Campana, 2011).

\section{Communication - the main function of art}

The process of communication is a well-known concept that expresses the relation of the individual with the environment. Communication provides the means by which the individual understands the environment. This is mainly because science, art or everyday practices are nothing more than components in the communication process that integrates them. Communication reflects the whole process of reason and its actions (Tran \& Stănciugelu, 2003). From the point of view of aesthetic experience, it can be said that art has a therapeutic role by providing a substitute for the perceived reality, as having a positive emotional load and by acting as a protector against the perceived negative emotional reality (Casey, 1971). The concept of art as a form of expression emphasises an externalisation process of the inner content that can be reduced to a process or an expression such as a gesture, a cry or a painting. There is a recurring tendency to identify expression and communication in art. Foss (beside. Casey, 1971) argues that the expression of the artist in the artistic act always represents communication. Margolis (beside. Casey, 1971) observes how expression theory emphasises that art is a pattern of communication between artists and the audience. Through artistic expressiveness, the creative product communicates (Dewey, apud. Casey, 1971).

The expression is strictly related to the communication process: the creative product itself expresses and sends a specific message. The idea that written and verbal languages are superior means of communication is generally accepted. However, the artistic expression has the quality of performing the same communication function. Tolstoy states that while through words one individual transmits his thoughts to another, through art the creator transmits his feelings and emotions. Casey (1971) argues that special attention should be paid to the communication model proposed by Tolstoy, which places information transmission as a central concept. In this model, transmission is the action of transmitting through a communication channel in order to reach a certain destination. The act of transmission consists of three fundamental elements: a content to be transmitted, a medium or channel through which the content is transmitted and a recipient, a receiver of the transmitted content. Moreover, Tolstoy points out that in order to express a feeling lived in the past, it must first be relived in itself and then, through the movements, lines, colours, sounds or 
forms expressed in words, that feeling is transmitted for others so they can perceive and live in the same way, and this whole process is called 'art'. It can be distinguished as a first feature that differentiates the aesthetic experience from artistic expression and communication through art. The aesthetic experience is strictly limited to exploring the movements, lines, colours, sounds and shapes that Tolstoy regards as mere tools for a broader sensory, emotional experience (Casey, 1971).

\section{The role of art, artists and artistic education in community and social change}

Before exploring the idea of art and artistic education as social change agents, the contextual meaning of the community concept must be clarified. 'Community' means either a specific place or group of people, or a specific way of interaction and cooperation. Community is centred on local people and social relationships rather than external power, knowledge and resources. The community is built and develops through dialogue and collaborative inquiry rather than the external determination of needs and implementation of strategies to address them. Community life is participatory and focused on empowerment rather than treating community members as passive recipients (Mathie \& Cunningham, 2005).

The artist as an educator and social change agent has much in common with critical pedagogy (Freire, 1970). For example, art educators try to expand art education through the inclusion of visual culture based in critical pedagogy theory with the goal of empowering students to be thoughtful, reflective and active participants in society (Cumpana, 2011). Moreover, Jasper (1997) compares activists for social change with artists in the sense of their thoughtful creativity and material deprivation; in addition, the underlying reason of their work is a feeling of moral and personal calling that leads to the fusion of social and individual fulfilment. As Eyerman (2006) puts it, art can be perceived as a form social activity through which new identities and practices emerge and where individual and collective creation that can provide society with new ideas and identities. Furthermore, he emphasises that art, as a social movement, opens new territory for social, political as well as aesthetic experimentation (Eyerman, 2006).

The role of art and artists as educators includes various activities towards socio-political consciousness, empowerment and change. These actions are focused on building a democracy (Giroux, 1995) based on critical inquiry and thinking (Freire, 1970), and becoming active individuals in order to challenge political and cultural limiting forces (Giroux, 1995). The role of art in the community can include the communication and transmission of different perspectives and visions, and facilitation of dialogue towards political and social consciousness for participants and audience as well as the consolidation and expression of collective identity and solidarity (Cumpana, 2011). Last, but not least, working towards emancipation, it provides a critical transformation from 
hopeless submission to restrictive conditions to a readiness to change those conditions (Freire, 1970; Jasper, 1997). As Paşca (2014) nicely puts it, the aesthetic ideal has for a long time influenced the pedagogical ideal. The artists, through the art product, are playing the role of coordinator of the human spirit and representing a fundamental means in the evolution of social life. Moreover, art education comes to offer people some fundamental dimensions of art development stages and, thus, understanding of the dynamics of historical processes and the evolution of human consciousness (Rusu, 2014).

\section{Objectives}

The present study is part of a broader qualitative research which explored therapeutic aspects related to artists' creative process. The main research question guiding the study was how an artist's creative process contributes to an improved quality of life? The main purpose of this part of the research was investigating the role of artist, art and art education in the community. Two questions guided the present study: 1 . What is the role of art education in the community/society? and 2. How can art contribute to positive community development?

\section{Methodology}

Thirty-two professional artists participated in this study, representing a large spectrum of age and domains of art. The selection criteria were that artists must be actively involved in teaching practice as well in producing works of art. The sample included 15 women with ages between 22 to 56 and 17 men with ages between 21 and 64. The snow-ball sampling technique was used: artists were recommended by fellow artists and art professors from the local Art University. There were 6 painters, 1 film director, 2 fiction writers, 7 composers, 2 orchestra/choir conductors, 7 instrumentalists (piano, guitar, trombone, vocal, and cello players), 1 actor, 5 choreographers, and 1 sculptor. However, most of the participants were performing in multiple domains of art (actor and fiction writer, piano player and lyric writer, cello and electric guitar player, vocal jazz player).

The participants were contacted by phone and asked to participate in the research. A semi-structured interview and conversational guided by interview questions was employed in order to explore the thoughts, feelings and behaviors related to the role of art and artistic education in the community. The interviews were audio recorded and later transcribed. The duration of the interviews was from twenty minutes up to two hours and thirty minutes. The main method for data analysis consists of thematic analysis of the content.

\section{Results}

Tab. 1. Themes and categories that emerged from the qualitative analysis

\begin{tabular}{|c|c|c|c|}
\hline & Themes & Categories & Frequencies \\
\hline I. & Means of & 1. Empowerment and emancipation. Provoking & 25 \\
\hline
\end{tabular}




\begin{tabular}{|c|c|c|c|c|}
\hline \multirow{6}{*}{ 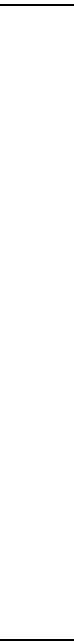 } & \multirow{6}{*}{$\begin{array}{l}\text { educational } \\
\text { intervention in the } \\
\text { community }\end{array}$} & & people to think differently & \\
\hline & & 2. & $\begin{array}{l}\text { By exposure to quality artistic creations, the } \\
\text { quality is given by the complexity of the } \\
\text { feelings aroused in the audience at the } \\
\text { exhibition }\end{array}$ & 21 \\
\hline & & 3. & $\begin{array}{l}\text { The therapeutic effect of exposure to artistic } \\
\text { creations }\end{array}$ & 10 \\
\hline & & 4. & $\begin{array}{l}\text { Identifying new ways of action by developing } \\
\text { the ability to improvise }\end{array}$ & 20 \\
\hline & & 5. & $\begin{array}{l}\text { Exposure to art leads to openness to novelty, } \\
\text { increases tolerance and diversity acceptance }\end{array}$ & 9 \\
\hline & & 6. & $\begin{array}{l}\text { The path to positive change by offering certain } \\
\text { roles }\end{array}$ & 7 \\
\hline \multirow[t]{2}{*}{ II. } & \multirow[b]{2}{*}{$\begin{array}{l}\text { Creator's } \\
\text { responsibility for } \\
\text { the impact of his } \\
\text { creation on the } \\
\text { audience }\end{array}$} & 1. & Shock art & 15 \\
\hline & & 2. & Responsibility for the communicated message & 17 \\
\hline \multirow[t]{4}{*}{ III. } & \multirow{4}{*}{$\begin{array}{l}\text { The semantic code } \\
\text { as a necessity for } \\
\text { understanding new } \\
\text { creations }\end{array}$} & 1. & $\begin{array}{l}\text { The art for the masses versus the art for the } \\
\text { initiates }\end{array}$ & 8 \\
\hline & & 2. & The progressive educational process & 5 \\
\hline & & 3. & Artistic expression laws & 6 \\
\hline & & 4. & Building a moral and values system & 5 \\
\hline IV. & \multicolumn{3}{|c|}{$\begin{aligned} \begin{array}{r}\text { Emotional } \\
\text { education }\end{array} & \text { reasoning }\end{aligned}$} & 15 \\
\hline $\mathrm{V}$. & The artist's need to & \multicolumn{2}{|r|}{ share the message through his creation } & 17 \\
\hline
\end{tabular}

\section{Theme 1. Means of educational intervention in the community}

The most common theme that emerged from the thematic analysis of the interviews emphasised the various methods of educational intervention in the community through art. What the artists intended when they were teaching or creating with educational purposes in mind could be structured into categories that include emancipation by means of provoking people to think and act differently, tolerance and diversity acceptance development and therapeutic effects of exposure to qualitative artistic creations. Empowerment and emancipation, the idea of change, tolerance, acceptance and the therapeutic value of art were found in most responses. With high frequency (25) the emancipation category emerged. As one teacher-writer participant says, the purpose of art education is to provoke people to think differently than in their usual way, valuing more the questions they ask themselves and not the answers:

'I appreciated those who made me think differently and then I would like to participate in this human celebration, this holiday called communication, exchange of thoughts, exchange of perspectives, I can attend as a teacher but there is not great reception when you give something with a spoon (...). You can have a teacher who changes your life, you can have a teacher who shows you how not to be. You can learn what you like, discover with the help of someone else, so a 
writer, an artist is actually a source of help. It may be more pleasant than a teacher to say so ... but it is something that will open more doors to you in fact about what you learn when you read something you like ... you discover in yourself, new feelings, new thoughts, new ways to perceive the reality'.

By showing people new ways of being, living, feeling and thinking, it can widen their universe. Artistic educated people have a greater openness to novelty; this is interesting because it can become a solution to increase the tolerance of a community. In general, art offers qualitative material in order to develop good thinking habits among individuals. Exposure to art can become an unforgettable experience for individuals as they learn to think critically about these pieces. Moreover, in terms of tolerance, imagination may be perceived as an enhancement vehicle. Cultivating the imagination, in turn, necessitates rich experiences embedded in learning environments, which will broaden our horizons and extend our thinking (Bentwich \& Gilbey, 2017). Dewey emphasises that art in all its forms allows us to 'enter, through imagination and the emotions they evoke, into other forms of relationships and participation than our own' (Dewey, 2008).

In this category also is the example given by a teacher-choreographer of being able to change people by offering them the chance to play a desired role. Artists assume a therapeutic mission and therapeutic effects for the creative product. This result describes the choice of an objective and the artist's belief that their art has therapeutic effects for the public. From the point of view of aesthetic experience, it can be said that art has a therapeutic role by providing a substitute for the negative perceived reality.

\section{Theme 2. Creator's responsibility for the impact of his creation on the} audience

The community intervention lies in the responsibility that the artists feel for the impact of their creation. Therefore, the artist can intervene in the community through the message expressed by their art which can trigger various debates and actions. Teachers feel a responsibility for the educational process but also for the cognitive/emotional message that their creative product transmits to the audience. Clearly, the artist's freedom also comes with responsibility for the message sent through his creation (frequency 17). One classical music composer intends to bring hope to his audience, another wants to create music that will benefit the audience. Although as an artist you are supposed to be free to do anything, this freedom must be controlled. A classical music composer spoke about freedom but also about control by emphasizing responsibility for the consequences of his creation on the audience.

Shock art means a creative product made specifically for the purpose of shocking, to surprise the audience (frequency 15). In some interviews reveal that shock art is made for money, for stimulating or surprising the receiver. Therefore, provoking debates, discussions and action in the community by means of transmitting a message that shocks either visual or audio. A painter finds justifications for the orientation towards the art of shock, in his conception 
nowadays world is too hasty and a shock is necessary to attract it, by idea or by plastic realization. In the same tone, a composer likewise justifies the search for darkness in music. Other artists are opposed to adopting the process of shocking the audience through art. A painter is completely against the currents that promote the shock in the artistic expression, considering the image offered as something monstrous, absurd, destructive, apocalyptic. A pianist beautifully describes the future for both shock and mass art, saying that art that was confined to only one segment of life in the world's lives did not stand the test of time, only the one that managed to include most of present life aspects.

Theme 3. The semantic code as a necessity for understanding new creations

First, for an effective impact of art education programmes in the community, the education process has to include the basic language of art. Learning the semantic code represents a necessity for understanding new creations. Both the sender and the receiver of the message must have a common language so that the message can be successfully received. The participants emphasised that the art education process has to be progressive (frequency 5) and some sort of associative learning must be employed. Therefore, the students have to associate a positive feeling with the artistic experience. A well-educated community in the sense of art appreciation would put end to the artist's dilemma of creating individualistic, original art versus creating easy art, which would sell easier. The easy art, or the art for the masses, requires low levels of (artistic) training and is easily accessible to everyone, but it limits the free expression of the artist.

Some artists believe that the purpose of artistic education in the community is to evoke positive feelings in people. A composer is constantly asking himself how to create music that is beneficial. For this composer, the purpose of art in the community is to elevate the human spirit to its potential, to make them collaborate. One painter considers that the orientation towards a beneficial evolution has a component of individual morality and another of culturalism, building a solid value system. According to an internalised value system, some artists avoid expressing negative emotions in their creative product, so they operate a selection of what is 'good' to express and what is not. Their moral code forbids them to pass on their negative feelings to others. Especially in the educational process, when they teach, the artist's main purpose, in general, is to express the positive.

Theme 4. Emotional education through the arts: diversity versus dichotomic reasoning

The main communication channel in the case of art is through the emotions it evokes. Music first communicates on an emotional level, which has an influence on the cognitive, whereas other forms of communication spread first to the cognitive level with the emotional level appearing later. The variety of emotions expressed through art determines acquiring, ordering emotions and forming an emotional repertoire for the community. Artists are always connected to their 
emotional side in order to be able to express it. In the case of an actress, choreographer and teacher, she recommends to others and to the students a clean and ordered emotional baggage and affective states; in order to access these emotions, the affective repertoire must be well maintained.

\section{Theme 5. The artist's need to share the message through his creation}

Last but not least, the most salient theme whenever the subject of art is in discussion encompasses the need for self-expressing and communion by sharing the message of the creative act. Self-expression, the need to give, communion by sharing the message, and the therapeutic value for the audience were found in most responses. As one director participant says: "But there is another feeling, another feeling that I say is very important in this field, these you do not do for yourself at home, you show them to others to enjoy and others [...] yes, it is to give. " Art is not made in isolation for individual purpose, is made to be shared, and it does not reach its ultimate meaning until it is received by the community or the audience.

\section{Discussions / Conclusions}

The results underline the important role of artists and art education as social change agents. Exposure to art leads to empowerment and emancipation by encouraging new ways of thinking. Therefore, in order to produce community change, art work must be oriented towards social and political consciousness, empowerment and change. Clearly, the art education process oriented towards community development has much in common with critical pedagogy principles. Art educators should seek to expand art education through the inclusion of visual culture based in critical pedagogy theory with the goal of empowering students to be thoughtful, reflective and active participants in society (Campana, 2011). Furthermore, ambiguous art products could offer well-suited material to facilitate critical thinking skills and can become unique experiences for students as they learn to think critically about these pieces (Bentwitch \& Gilbey, 2017).

Art presumes a constant attempt to understand and see from another's perspective, both for the artist and for the audience. This, in turn, leads to reflection and questioning of one's own place in relationship to others. This is, in fact, the reason why art and art education contribute to tolerance building and diversity acceptance in the community. Being in line with the critical pedagogy assumption that reality and knowledge are not fixed and absolute but, rather, dependent on one's experiences, ways of interpreting those experiences and subject to transformative actions based on those interpretations. (Kincheloe, 2004). Art education with an emphasis on dialogue, investigation and inquiry as methods rather than the direct transfer of knowledge from teacher to student could contribute to community development.

The results showed important consequences for art education in the community in the sense that art exposure could develop feelings for certain moral, social and emotional issues to which the community could otherwise remain 
blind. Without an appreciation of the subtleties of particularised feeling expressed in the arts, one's perception and emotional response would be restricted to those areas of life with which those arts are dealing, to a relatively bland, promiscuous level. The more one comes to understand an art form, the more one develops the capacity for fine discriminations of interpretation and, therefore, for finely discriminated emotional feelings (Best, 1978).

Another important aspect of the results is the contribution of art education in building a moral value system. In trying to determine whether or not art has moral value, Tolstoy's definition is very useful. He argues that a perfect work of art is one in which the content is important and meaningful to all people and, therefore, will be moral. Tolstoy emphasises that in this case, the way of expression will be very clear and intelligible for all and, therefore, beautiful, and the creator's relationship with his work will be completely sincere and, therefore, true (Tolstoy, 1996). Tolstoy does not define art by its ability to express beauty, but it defines art by emphasizing its ability to communicate concepts of morality. For Tolstoy, aesthetic values are defined by moral values. Besides being a means of communication art is an important means of expressing any experience, about any aspect of the human condition.

\section{References}

1. Bentwich, M. E., \& Gilbey, P. (2017). More than visual literacy: art and the enhancement of tolerance for ambiguity and empathy. BMC medical education, 17(1), 200.

2. Best, D. (1978). Emotional education through the arts. Journal of Aesthetic Education, 12(2), 71-84.

3. Campana, A. (2011). Agents of possibility: Examining the intersections of art, education, and activism in communities. Studies in Art Education, 52(4), 278291.

4. Dewey, J. (2005). Art as experience. London: Penguin.

5. Eyerman, R. (2006). Toward a meaningful sociology of the arts. In Eyerman R. \& McCormick, L. (Eds.), Myth, meaning, and performance: Toward a new cultural sociology of the arts (pp. 13-34). London: Paradigm Press.

6. Freire, P. (1970). Pedagogy of the oppressed. New York: Continuum.

7. Gablik, S. (1995). Connective aesthetics: Art after individualism. In Lacy, S. (Ed.), Mapping the terrain: New genre public art (pp. 74-87). Seattle: Bay Press. 8. Giroux, H. (1995). Borderline artists, cultural workers, and the crisis of democracy. In Becker, C. \& Wiens A. (Eds.), The artist in society: Rights, roles, and responsibility (pp. 4-14). Chicago: New Art Association/New Art Examiner Press.

9. Jasper, J. M. (1997). The Art of Moral Protest. Chicago: The University of Chicago.

10. Kincheloe, J. (2004). Critical pedagogy primer. New York: Peter Lang 
Publishing.

11. Mathie, A., \& Cunningham, G. (2005). Who is driving development? Reflections on the transformative potential of asset-based community development. Canadian Journal of Development Studies/Revue canadienne d'études du développement, 26(1), 175-186.

12. Pașca, E.M. (2014). Conceptions of the role of music in education. In Rusu, M. (Ed.), Art and Personality. The role of art education. Iași: Ars Longa.

13. Rusu, M. (2014). Introduction. In Rusu, M. (Ed.), Art and Personality. The role of art education. Iași: Ars Longa.

14. Tolstoy, L. (1995). What is Art? London: Penguin.

15. Tran, V. \& Stănciugelu, I. (2003). Teoria comunicarii. Bucuresti: Comunicare.ro.

16. Wolff, J. (1990). Postmodern theory and feminist art practice. In Postmodernism and society. Palgrave, London. 